\title{
Greening of Malaysian School Human Resource Management by Green Intellectual Capital and Healthy Organization
}

\author{
Abdul Jalil Ali, Abdul Ghani Kanesan Abdullah, Al Amin Mydin, Aneela Sheikh
}

School of Education Studies, Universiti Sains Malaysia, 11800 Penang, Malaysia

Correspondence Author: Abdul Jalil Ali, School of Educational Studies, Universiti Sains Malaysia, 11800, Penang, Malaysia.

E-mail: jalil@usm.my

Received date: 12 January 2018, Accepted date: 10 March 2018, Online date: 20 March 2018

Copyright: @ 2018 Abdul Jalil Ali et al. This is an open-access article distributed under the terms of the Creative Commons Attribution License, which permits unrestricted use, distribution, and reproduction in any medium, provided the original author and source are credited.

\begin{abstract}
Most previous studies has shown an association between green human resource management, green intellectual capital and healthy organization: however, in Malaysia little is known about the GHRM implementation through which this relationship occurs especially in school context, The aim of current study is to examine the mediating effects of green intellectual capital on the relationship between green human resource management and healthy organization in Malaysian high performing secondary schools. The data for this study were collected from 280 trained teachers high performing National Secondary Schools across the three States of Northern Peninsular Malaysia. The findings reveal that there is a significant direct effects of green human resource management and green intellectual capital on healthy organization. Meanwhile, green intellectual capital has a full mediation effect on the association between green human resource management and healthy organization. Thus, the findings show added value that green intellectual capital provides when used as an enabler of human resource management; this would help school management about the potential of green intellectual capital in increasing healthy organization demands for environmental sustainability.
\end{abstract}

Key words: Green Human Resource management, Green Intellectual Capital, Healthy organization, Malaysian schools

\section{INTRODUCTION}

Throughout this millennium, environmental sustainability has become a significant contemporary interest, a prevalent issue debated by the policy-makers, public opinion and practicing managers [1-4]. Thus, the environmental management has become an important field of management research and body of knowledge [5-7]. A recent stream of the empirical study had focused on the role played by human resource management practices aiming at developing environmental performance or Green Human Resource Management -GHRM [8-9]. GHRM is referred to the activities that involve in development, implementation and ongoing maintenance of a system that aims at making employees of an organization Green [10]. It also refers to the policies, practices and systems that make employees of the organization Green for the benefit of the individual, society, natural environment, and the business [11]. Subsequently, the purpose of Green HRM is to generate, enhance and retain Green environment within each employee of the organization so that he or she gives a maximum individual contribution to environmental sustainability [6]. However, considerable uncertainty remains regarding the role of GHRM in school setting especially in Malaysia to achieve environmental sustainability [8]. Therefore, the first knowledge gap addressed by this study, from chain management point of view have pointed that GHRM practices do have positive relationship in developing and sustaining environmental performance such as healthy organization [12]. Research in profitable organizations has shown an association between GHRM practice and their proactive adoption of environmental practices such as intellectual capital IC and sustainable performance [13-15]. Whilst, IC is the total stocks of all intangible assets, knowledge, and capabilities of a firm that could create values or competitive advantages and achieves its excellent goals [16]. While Miles [17] coined another variable also has positive influence by green HRM is healthy organization $[\mathrm{HO}]$ to describe the extent to which organization resolves the basic problems of survival, growth and development. A healthy organization, by definition is one that displays categories of task, maintenance, and growth and development needs, which operating together provide the ideal environment for attainment of optimal human development and functioning [16]. However, within this body of theoretical and empirical research, studies linking the here variables not been conducted in the Malaysian school setting; and there is no published research exploring the mediating effect of IC on the association between GHRM practices and $\mathrm{HO}$ in Malaysian school context. Therefore, this study seeks to address this as second knowledge gap. Apparently, the Malaysian Department of Environment [DoE] in the Ministry of Natural Resources and Environment; the Ministry of Education, Malaysia, and Institute for Environment and Development [LESTARI], encourage at school for a more environmental awareness society [18]. In school context, GHRM policies encourage the sustainable use of resources within school organization to promote the cause of environmentalism and in the process, create improved school community morale and satisfaction. Improved school community morale, stronger public image, increased parents confidence, students loyalty and brand recognition, position as an school organization of choice, increased workforce productivity and school community retention are few of the many advantages and benefits an organization can have by implementing and developing such GHRM techniques $[8,19]$. The school provides a framework for the teachers, to establish social organizational ambience such as work culture and work climate, by which they are influenced and in turn influence themselves. Teachers provide the social and human capital to which the students are exposed and hence are a key element in determining the effectiveness and productivity of a school. Creating healthy organizations is about the development of appropriate enabling management process and practices that intervene all organization-wide systems that will contribute to overall performance. A truly healthy organization, is the one which strategically integrates employee well-being into its business objectives and reinforces it through established practices on leadership support, learning culture, healthy job quality, and people friendly HRM practices [20]. Hence, indirectly school organization play an important role in realizing the importance of GHRM and green intellectual capital in school. 
However, in Malaysia little is known about the GHRM implementation through which this relationship occurs. Meanwhile the volume of scholarly work focusing on GHRM, Green Intellectual Capital and Healthy Organization in school remains unexplored especially in school context. Most previous studies on GHRM, Green Intellectual Capital and Healthy Organization have been conducted in Western countries, and the generalizability of these findings to other parts of the world is questionable. However, for some reasons, these variables were unexamined using cross-cultural in Malaysian educational settings. Therefore, current attempt is to explore the mediating role of green intellectual capital on the relationship between GHRM and healthy organization in Malaysian high performing secondary schools.

\section{Related Literature Review and Hypothesis Development:}

Green Human Resource Management (GHRM):

GHRM is defined as a set of specific HRM practices that enable and sustain a proactive approach to environmental management and the achievement of high performance outcomes in relation to environmental sustainability and other types of business objectives [8]. Meanwhile GHRM practices refer to using every employee touch point or interface to promote sustainable practices and increase employee awareness and commitments on the issues of sustainability [9-10]. The initiatives of GHRM has become an important factor in forward-thinking education institution around the world. Consequently, this initiatives help schools to find alternative ways to cut cost without losing their top talent which is furloughs and part-time work. It involves undertaking environment-friendly HR initiatives resulting in greater efficiency, lower costs and better employee (school staff) engagement and retention which in turn, help organizations to reduce employee (school staff) carbon footprints by the likes of electronic filing, car sharing, job-sharing, tele-conferencing and virtual interviews, recycling, telecommuting, online training, and energy-efficient office [21-22].

\section{Green Intellectual Capital (GIC):}

Scholars defined Intellectual Capital in several ways. Human capital represents employees "cumulative inferred knowledge", which originated from genetic inheritance, education, experience, and attitudes regarding life and business [19]. However, existing scholars have conceptualized green intellectual capital as intellectual capital to satisfy the environmental management needs [7,18-19]. Meanwhile, in the current study, GIC can be seen as a subset of the intellectual capital. The creation, transfer and application of knowledge enable companies to offer higher added-value of green product and services, which in turn will increase the market value [23]. The new approach of solving the existing environmental problems depends heavily on how knowledge resources are deployed [24], which have been discussed in the emerging concept of green intellectual capital. Existing scholars have conceptualized green intellectual capital as intellectual capital to satisfy the environmental management needs $[7,18]$. But in the context education, the empirical findings based on the GIC never been explore by any researchers. If this had been done, then the gap between the market value and book value (Intellectual Capital) will also increase due to the contribution of knowledge resources about environmental management (green intellectual capital) in school.

Healthy Organization $(\mathrm{HO})$ :

De Smet and his colleagues [25], conceptualized health of organizations emerges out of a metaphor "performance and health" which improves when cared for and deteriorates when ignored, thus signifying the importance of employees' well-being for business profitability, the central notion of healthy organization approach As such, humanistic psychologists [26], medical professionals, management scholars, and so on have played the central role in the development of this concept and provide backdrop to the current focus. This new thinking has also been reinforced by recent advances in the management of human resources [HR], making it imperative that employees' well-being and organizational performance draw on each other strengths. School climate can also be understood by applying the metaphor of health. Miles [17] describes a 'healthy' school as one that exhibits reasonably clear and reasonably accepted goals (goal focus); communication that is relatively distortion-free vertically, horizontally, and across boundary lines (communication adequacy); equitable distribution of influence to all levels of the organization (optimal power equalization); and effective and efficient use of inputs, both human and material (resource utilization). The healthy school reflects a sense of togetherness that bonds people together (cohesiveness), a feeling of well-being among staff (morale), self-renewing properties (innovativeness), and an active response to its environment (autonomy and adaptation). The healthy school also maintains and strengthens its problem-solving capabilities (problem-solving adequacy) [27].

\section{GHRM, GIC and HO}

Cherian and Jacob [5] published a comprehensive list in respect of studies on Green HRM. Based on their reviewed studies, very recent studies done in 2010 and 2011. Sarkis et al. [28] in his finding the impact of stakeholder pressure on environmental management principles with data type Primary-Survey approach. The finding of this study was eemployees presented with better training have better perception of environmental management systems. Jabbour et al. [27] had done a study based on training, recruitment and rewards with the impact of HRM on Environmental Management System and found human dimensions has a positive impact implementation of green management principles.

Empirical studies on healthy organization was significant in at least two disciplines, educational settings with the development of a valid OHI by Hoy and Feldman [29] and not for profit institutions. These studies examined the context of school environment, teacher's functioning, work quality, efficacy of schools, and indicator of its social-psychological status. Among studies in business organizations, Aryee, law \& Law [30] proposed organizational health concept as an extension of occupational health psychology with a clear organizational focus. Danna and Griffin [31] review-related employee well-being to organizational effectiveness and functioning.

The classification of green intellectual capital was adapted from Johnson and Bontis [32] work. The study classified green intellectual capital into three types, namely green human capital, green structural capital and green relational capital. A similar classification has also being proposed by Liu [19], another study conducted in Taiwan. The author has defined green intellectual capital as the integration of green and environment knowledge sources and knowing capability of companies for improving competitive advantage.

In a case study conducted in Spanish firms, Lopez-Gamero, Zaragoza-Saez, Claver-Cortes and Molina-Azorin, [33] contended that sustainability should be extended from relational capital to the human capital, structural capital and relational capital. The creation of the sustainable intellectual capital construct is described as the sum of all knowledge to be leveraged by organization in the process of conducting environmental management to gain competitive advantage. Among the three studies, Chen [16] model stands out as one of the major points of reference in other researches that utilized green intellectual capital variables. Impact of green HRM practices on teamwork, organizational culture had been conducted by Garavan [34] on training and development. He found that employees with better training is vital to promote a good environmental management system in any organization and build an effective organizational culture. Burke \& Gaughan [35] found that professionals were concerned with the environmental stance of a company on the study on impact of environmental principles on recruitment. Besides, Jabbour et al. [36] again done a research on impact of HRM and environmental management on organizational performance of the company. In this study shows that human dimension impacts organizational performance as well as mediates environmental management system implementation. Daily et al. [37] on his study on impact of training and development related to environmental management on performance of employees found that all other facets of HRM related to implementation of Green management principles are directly associated with good training.

In the most recent researches, have recommended a process-based model of healthy organization as they considered organizations as having system properties. According to Lowe, Schellenbefg \& Shahnon [38] defines a healthy organization as one whose culture, climate and practices create an environment that promotes employee health and safety as well as organizational effectiveness. In a research on relationship between green intellectual capital and competitive advantage in Taiwan, [16] has described green intellectual capital as "total stocks of all kinds of intangible assets, knowledge, capabilities and relationships, and others related to environmental protection or green innovation on the individual level and the organization level within a company".

\section{Hypotheses:}

This research focuses on three hypotheses as mention below: -

H1: GHRM has a significant relationship with HO.

H2: GHRM has a significant relationship with GIC 
Citation: Abdul Jalil Ali, Abdul Ghani Kanesan Abdullah, AlAmin Mydin, Aneela Sheikh, 2018. Greening of Malaysian School Human Resource Management By Green Intellectual Capital and Healthy Organization. Advances in Natural and Applied Sciences., 12(3): 46-50.

H3: GIC has a significant mediating effect in the relationship between GHRM and HO

Methodology:

Survey questionnaires were administered to the respondents in their work settings via post and including with each survey was a letter from the researchers indicating the general nature of the survey and assuring all respondents that their individual responses would remain anonymous.

\section{Participants:}

The data for this study were collected from 280 trained teachers randomly from 20 National High Performing Secondary Schools across the three States of Northern Peninsular Malaysia, namely Penang, Kedah and Perlis. The pre-requisite for teacher participation as respondents in this study was that the teachers must have worked for at least 3 years. The sample consists of 64 percent female respondents, mean age is 34.78 years (Standard Deviation =7.51), while an overall of 89 percent respondents are with working experience of more than 4.88 years $(\mathrm{SD}=1.26)$.

Measures:

A set of questionnaires were employed in this study on five-point Likert scales, ranging from [1] "strongly disagree" to [5] "strongly agree" measuring GHRM, GIC and OH. The GHRM developed by Cherian and Jacob [5] was used to measure GHRM in this research. It is a self-report instrument designed to measure the four dimensions of GRHM namely green behaviour, green competencies, green results and green attitude through 14 items. For the purpose of this study this construct was measured as unidimensional with Cronbach Alpha was .90. Meanwhile intellectual capital was measured using an instrument developed by Cherian and Jacob, This construct was examined by using 14 items. The Cronbach Alpha was .89. HO was measured using an existing scale, Organizational Health Inventory developed by Hoy and Feldman, [39]. The items of HO were tested by 33 items and the Cronbach Alpha was .91

Research Findings:

Descriptive Findings:

The results of correlation matrix [Table 1] shows the significant relationships between the hypothesized variables. Thus the findings revealed that GRHM and GIC are relate positively with HO. Meanwhile GIC and HO intercorrelate positively.

Table 1: Correlation results of variables

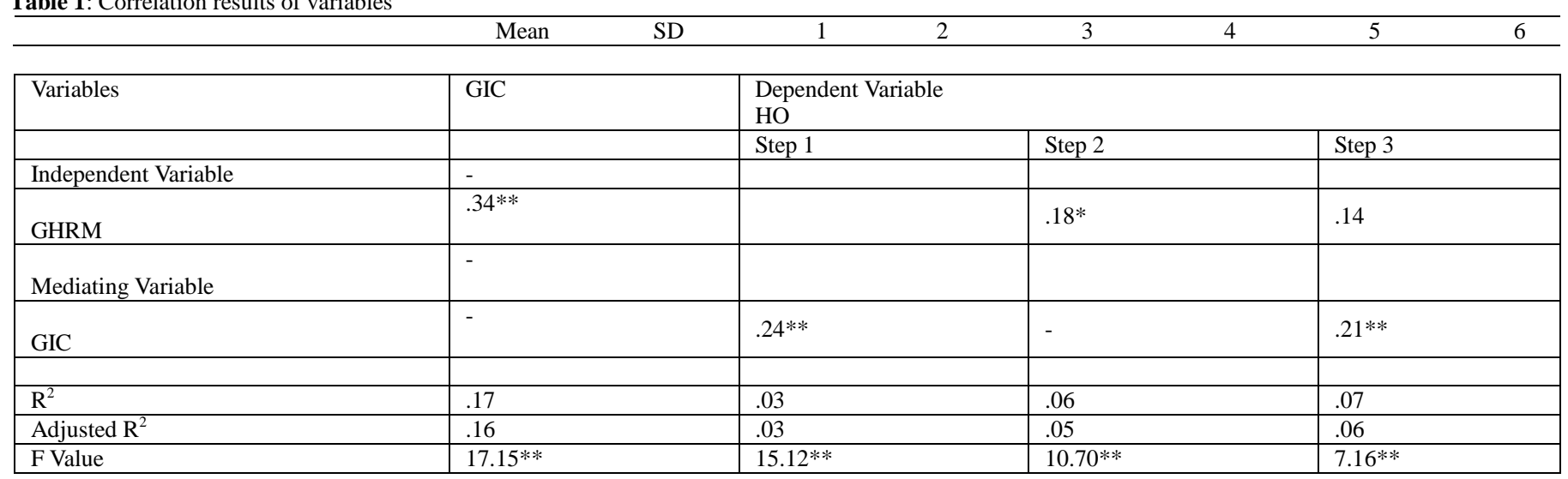

Table 2: The mediation of GIC in the relationship between GHRM and HO

\begin{tabular}{|c|c|c|c|c|c|c|c|c|c|}
\hline & $*$ sig. at $p<.05$ & & & & & & & & \\
\hline 1 & Gender & - & - & - & & & & & \\
\hline 2 & Age & 34.78 & 7.51 & -.06 & - & & & & \\
\hline 3 & Teaching Experience & 4.88 & 2.32 & -.03 & -.03 & - & & & \\
\hline 4 & GHRM & 3.74 & .89 & -.07 & -.05 & $.38 * *$ & - & & \\
\hline 5 & $\mathrm{HO}$ & 3.61 & .61 & -.05 & -.08 & $.41 * *$ & $.63^{* *}$ & - & \\
\hline 6 & GIC & 3.44 & .50 & -.01 & -.09 & $.58 * *$ & $.48 * *$ & $.61 * *$ & - \\
\hline
\end{tabular}

\section{Hypothesis Testing:}

Hierarchical regression analysis (table 2) was deployed to test the degree to which GIC mediates the relationship between GHRM and HO in this research. The procedure suggested by Baron and Kenny, [40] was used to test the mediation effects. Table 2, shows the results of the mediation tests: a) GHRM predict $6 \%$ of unique variance of $\mathrm{HO}$, thereby meeting the first condition for mediation and support $\mathrm{H1}$; (b) GHRM predict $17 \%$ of GIC. Thus this findings support $\mathrm{H} 2$ and the second condition for meadiation; (c) finally when the independent (GHRM) and the mediating variable (GIC) enter in the regression for predicting HO, the relationship between GHRM and HO decreases (Beta values decreases from .18 to .14 and not significant). Thus, the findings revelled a full mediation of GIC in the relationship between GHRM and $\mathrm{HO}$ (H3 supported).

\section{Discussion and Implication:}

\section{The Influence of Green Human Resource Management on Healthy Organization:}

GHRM is a significant predictor of HO in an organization in this school. According to Jabbour and Santos, [41], GHRM has to provide the competencies needed for the continuous improvement of the organizational environmental performance. Thus, GHRM is competent in secondary schools and influence HO at workplace and this shows that the connection between teachers and among teachers and students in secondary schools. Meanwhile Garavan, mentioned that, it does not matter whatever the job or the field of specialization of the employee, but they should able to create a great outcome. Hence, through GHRM where principal's concern for the welfare of school staff, combined with high expectations from the principal for school staff performance to archive green in school organization. According to Milfont and Duckitt, [42], right attitude is having appropriate beliefs, feelings and intention to behave with regard to greening, and it should be identical to the one. Thus, green attitude influenced rresource iinfluence to combines the ability of principals to influence superiors and their ability to procure material supplies for the school.

Green social capital is significant predictor of institutional integrity, collegial leadership, resource influence and academic emphasis. According to Edvinsson and Malone, [43], green social capital should signify the organization's link to the market it operates especially green supplier and green customer and other stakeholders. Hence, green social capital influenced iinstitutional iintegrity to which teachers feel the institution (school) and its administration (decision makers) are able to proceed with their mission (educating students) without undue influence from outside sources. Besides, green social capital also influenced $c$ collegial lleadership and resource influence where principals play an important role by concern and influence for the welfare of school staff by development calls for 
Citation: Abdul Jalil Ali, Abdul Ghani Kanesan Abdullah, AlAmin Mydin, Aneela Sheikh, 2018. Greening of Malaysian School Human Resource Management By Green Intellectual Capital and Healthy Organization. Advances in Natural and Applied Sciences., 12(3): 46-50.

environmentally friendly materials and technologies. Lastly, green social capital influenced aacademic emphasis where school's emphasis on high expectations for student achievement to archive greening in school [44].

\section{The Influence of Green Human Resource Management on Green Intellectual Capital:}

Green behaviour and green result are significant predictor of green human capital. As environmental sustainability requires behavior change by employees [45] and all members of an organization at all levels are required to exhibit a positive behavioral change. Thus, green behaviour influenced on green human capital by address the environmental issues possessed by individuals, shared and communicated throughout the organization in terms of knowledge, skills and awareness [46]. Besides, green results are outcomes or outputs which are environmentally friendly to which the employee has produced green outcomes which influenced green human capital to provides an opportunity to engage employees in environmental problem solving through green teamwork and enhance their awareness of the need for environmental control, increases their ability to adapt change, and develops a proactive attitude toward environmental issues.

Green behaviour is significant predictor of green innovation capital. Green behaviour where the employee engages in positive actions aimed at helping the organization as a whole influenced green innovation capital, which represent the ability of a company to generate new knowledge, new product and any creative ideas aimed at addressing the environmental issues to achieve greening.

Green attitude and green result are significant predictor of green organization capital. Green results are viewed as employee green performance of job which contributes to green organizational performance and right attitude corresponds to the management and generation of knowledge in addressing the environmental issues effectively that supporting employees productivity.

\section{The Mediating Role of GIC on GHRM and HO:}

The finding reveal that GIC act as full mediator on the relationship between green attitude and resource influence. GIC as intellectual capital to complement the environmental management needs [19]. Green social capital should signify the organization's link to fulfill the needs of society especially school organizations. According to Sharma, [47], right attitude (favorable) means having an appropriate beliefs (cognitive), feelings (affecting) and intention to behave (behavioral) with regard to greening. It does not matter whatever the job or the field of specialization of the employee is. What matters is that he or she should have a right attitude (favorable) about greening.

Hence, the green attitude has an effect on resource influence where combines the ability of principals to influence superiors and their ability to promote a right attitude about green towards school organization and school staff. Whereas collaborative relationships among the organization member is vital as the new outcome for environmentally friendly materials and technologies. Feedback from customer will motivate firms to adopt green innovations and satisfy their needs, whilst improving their environmental performance. In other word, the effect of green attitude on resource influence must get green social capital.

According to above statement, although most of the high performing schools in Malaysia have begun to understand the importance of environmental friendly, but this matter is still haven't be explore widely in Malaysia. Thus, from the finding can conclude that secondary schools in Malaysia especially in Penang state had some dimensions influenced on healthy organization in schools as the states' slogan is "Penang Clean and Green" and can become an example in promoting greening to other schools as stated in the problem statement of this study.

\section{Implication of the Findings:}

Theoretical Implication:

In Malaysia, the volume of empirical research focusing on GHRM, GIC and HO in school still remains small, so these themes have many gaps to be filled theoretically and empirically. The finding shows that the level of GHRM, GIC and HO are still in average level. This shows that most of the secondary schools in Malaysia are not aware of these issues. Hence, this study mainly focuses on these fields to make embedding sustainability in education context. Consequently, a suitable theory should be developed based on education context and teachers have to be well trained to practices the developed theory to produce an effective greening practice in education environment.

\section{Practices:}

Schools administrators should be expose and develop the importance of promoting GHRM and GIC for HO. A model should be created base on the Malaysian school context so that it can enhance GHRM and GIC. Schools administrators have to make sure that all the academic and non-academic staff are aware of green practice in the school. Furthermore, schools administrators have to make sure all teachers undergo proper greening education or attend courses related to enhance greening practices in school environment.

\section{Educational Management:}

The results of this study give an important contribution to the school administrations, state educational department level and also to the Ministry of Education Malaysia. This study also shows the importance of practicing GHRM and GIC to produce healthy organization in school. The finding shows that GHRM and GIC and this suggest to enhancement awareness program to the teachers should be prepared by the Ministry of Education or State Department of Education.

\section{CONCLUSION:}

To conclude, the findings here highlight the significant mediating role of GIC in the implementation of GHRM approach to HO that successfully promotes environmental sustainability in Malaysian schools. In particular, findings indicate the importance to Malaysian school managers, if they wish to have healthy organization environment, then cannot neglects to recognize the fundamental role of GIC have in maximizing the effects of GHRM. The findings also suggest that lack of GHRM practices relatively would decrease the impact on HO and GIC ties. In conclusion, we suggest that to enhance a healthy organization within the schools, the importance of green human resource management and green intellectual capital practices should be taken into serious considerations.

\section{REFERENCES}

1. McKinsey. (2014). Sustainability's strategic worth: McKinsey Global Survey results. McKinsey report. Retrieved from http://www.mckinsey.com/insights/sustainability/sustainabilitys_stra tegic_worth_mckinsey_global_survey_results

2. De Lange, D. E., Busch, T., \& Delgado-Ceballos, J. (2012). Sustaining sustainability in organizations. Journal of Business Ethics, $110,151-156$ doi:10.1007/s10551-012-1425-0

3. Dangelico, R. M., \& Pujari, D. (2010). Mainstreaming green product innovation: Why and how companies integrate environmental sustainability. Journal of Business Ethics, 95, $471-486$.

4. Kassinis, G., \& Vafeas, N. (2006). Stakeholder pressures and environmental performance. Academy of Management Journal, 49 , 145 - 159 doi:10.5465/AMJ.2006.20785799

5. Cherian, J., \& Jacob, J. (2012). A study of Green HR practices and its effective implementation in the organization: A review. International Journal of Business and Management, 7, 25-33.

6. Opatha, H. H. D. N. P. \& Anton Arulrajah, A. (2014), Green Human Resource Management: A Simplified General Reflections, International Business Research, Vol. 7, No. 8, pp. 101-

7. Chen., Y.S \& Chang C.H. (2013)'. Enhance Environmental Commitments and Green Intangible Assets toward Green Competitive Advantages: An Analysis of Structural Equation Modelling (Sem), Qual Quant, 47, 529-43

8. Renwick, D. W. S., Redman, T., \& Maguire, S. (2013). Green human resource management: A review and research agenda. International Journal of Management Reviews, 15(1), 1 - 14. doi:10.1111/j.1468-2370.2011. 00328.x

9. Welford. R. (2000). Corporate Environmental Management, towards sustainable development. British Library. ISBN 978-1-85383-660-2 
Citation: Abdul Jalil Ali, Abdul Ghani Kanesan Abdullah, AlAmin Mydin, Aneela Sheikh, 2018. Greening of Malaysian School Human Resource Management By Green Intellectual Capital and Healthy Organization. Advances in Natural and Applied Sciences., 12(3): 46-50.

10. Jackson, S.E., Renwick, W.S.,Jabbour, C.J.C., \& Muller-Camen, M (2011), State-of-the-Art and Future Directions for Green Human Resource Management: Introduction to the Special Issue, German Journal of Research in Human Resource Management, 25:2, pp. 99-116.

11. Jabbour, C. J. (2013). Environmental training in organisations: From a literature review to a framework for future research. Resources, Conservation and Recycling, 74, 144 - 155. doi: 10.1016/j.resconrec.2012.12.017

12. Jackson, S., \& Seo, J. (2010). The greening of strategic HRM scholarship Organization.

13. Lai, K., \& Wong, C. W. Y. (2012). Green logistics management and performance: Some empirical evidence from Chinese manufacturing exporters. Omega, 40, 267 - 282. doi: 10.1016/j.omega. 2011.07.002

14. Dutta, S. (2012). Greening people: A strategic dimension. ZENITH: International Journal of Business Economics \& Management Research,2, 143-148.

15. Chen,Y.S. (2008). 'The Positive Effect of Green Intellectual Capital on Competitive Advantages of Firms', Journal of Business Ethics, 77,271-86.

16. Edvinsson,L. \& M.S. Malone (1997). Intellectual Capital. Realizing Your Company's True Value by Finding Its Hidden Brainpower (New York: Harper Collins Publishers, Inc).

17. Miles, M. B. (1965). Planned change and organizational health, figure and ground. Change Processes in the Public Schools. Oregon University, Center for the Advanced Study of Educational Administration, 11-34.

18. Baharum, M. R. \& M.Pit.'Determining.(2009). A Conceptual Framework for Green Intellectual Capital, Journal of Facilities Management,7, $267-82$.

19. Liu, C.C. (2010). Developing Green Intellectual Capital in Companies by Ahp, in Supply chain management and information systems (SCMIS) 2010 8th International Conference, , pp. 1-5.

20. Mandip, G. (2012). Green HRM: People management commitment to environmental sustainability. Research Journal of Recent Sciences, 1, $244-252$.

21. Mampra, M. (2013, January 6-9). Green HRM: Does it help to build a competitive service sector? A study in Proceedings of tenth AIMS International Conference on Management (pp. 1273-1281).

22. Muster, V., \& Schrader, U. (2011). Green work-life balance: A new perspective for Green

23. Milfont, T. L., \& Duckitt, J. (2010). The environmental attitudes inventory: A valid and

HRM. Zeitschrift Fur Personal for Schung, 25, 140-156. attitudes. Journal of Environmental Psychology, 30(1), 80-94.

24. Mathapati, C. M. (2013). Green HRM: A strategic facet. Tactful Management Research Journal, 2(2), 1-6.

25. De Smet A, Loch M, \& Schaninger B. Anatomy of a healthy corporation. (2007). The Mckinsey Quarterly,1-11.

26. Vroom VH. (1964). Work and motivation. New York: John Wiley and Sons.

27. Jabbour, C. J., Santos, F. C. A., \& Nagano, M. S. (2010). Contributions of HRM throughout the stages of environmental management: Methodological triangulation applied to companies in Brazil. International Journal of Human Resource Management, 21, 1049 - 1089.

28. Sarkis, J., Gonzalez-Torre, P. L., \& Adenso-Diaz, B. (2010). Stakeholder pressure and the adoption of environmental practices: The mediating effect of training. Journal of Operations Management, 28, 163 - 176. doi:10.1016/j.jom.2009.10.001

29. Hoy, W. K. \& Feldman, J. A. (1987). Organizational health, the concept and its measure. Journal of Research and Development in Education, $20(4), 30-37$.

30. Aryee, L. Y., Law, S., \& Law, K. S. (2007). High-performance human resource practices, citizenship behavior, and organizational performance: A relational perspective. Academy of Management Journal, 50, 558 - 577. doi:10.5465/AMJ.2007.25525821

31. Danna K, Griffin RW. Health and well-being in the workplace (1999): A review and synthesis of the literature. Journal of Management, 25,357-84

32. Johnson and Bonits (1999). https://www.coursehero.com

33. Lopez-Gamero,M. D., P. Zaragoza-Saez, E. Claver-Cortes, \& J. F. Molina-Azorin (2011).Sustainable Development and Intangibles: Building Sustainable Intellectual Capital, Business strategy and the Environment,20,18-37.

34. Garavan, T. N. (1995). Stakeholders and strategic human resource development. Journal of European Industrial Training, $19,11-16$. doi:10.1108/03090599510095825

35. Burke, S., \& Gaughran, W. F. (2007). Developing a framework for sustainability management in engineering SMEs. International Journal of Computer Integrated Manufacturing, 23, 696 - 703. doi:10.1016/j.rcim.2007.02.001

36. Jabbour, C. J. (2013). Environmental training in organisations: From a literature review to a framework for future research. Resources, Conservation and Recycling, 74, 144 - 155. doi: 10.1016/j.resconrec.2012.12.017

37. Daily, B. F., Bishop, J. W., \& Massoud, J. A. (2012). The role of training and empowerment in environmental performance: A study of the Mexican Maquiladora industry. International Journal of Operations \& Production Management, 32, 631 - 647. doi:10.1108/01443571211226524

38. Lowe GS, Schellenberg G, \& Shannon HS. (2003). Correlates of employees' perceptions of a healthy work environment. Am J Health Promote, 17,390-9.

39. Hoy, W. K. \& Feldman, J. A. (1987). Organizational health, the concept and its measure. Journal of Research and Development in Education, 20(4), 30-37

40. Baron, R. M., \& Kenny, D. A. (1986). The moderator-mediator variable distinction in social psychological research: Conceptual, strategic, and statistical considerations. Journal of Personality and Social Psychology, 51, 1173-1182.

41. Jabbour, C. J. C., Santos, F. C. A., \& Nagano, M. S. (2010). Contributions of HRM throughout the stages of environmental management: Methodological triangulation applied to companies in Brazil. The International Journal of Human Resource Management, 21, 1049-1089.

42. Milfont, T. L., \& Duckitt, J. (2010). The environmental attitudes inventory: A valid and reliable measure to assess the structure of environmental attitudes. Journal of Environmental Psychology, 30(1), 80-94.

43. Edvinsson,L. \& M.S. Malone (1997). Intellectual Capital. Realizing Your Company's True Value by Finding Its Hidden Brainpower (New York: Harper Collins Publishers, Inc).

44. Hoy, W. K., Tartar, C. J., \& Kottkamp, R. B. (1991). Open schools/healthy schools: 2002, from http://www.coe.ohio-state.edu/whoy/on-line\%20books_4.htm

45. Harvey, G., Williams, K., \& Probert, J. (2013). Greening the airline pilot: HRM and the 'green' performance of airlines in the UK. International Journal of Human Resource Management, 24,152 - 166. doi:10.1080/09585192.2012.669783

46. Paauwe, J., \& Boselie, P. (2003). Challenging 'strategic HRM' and the relevance of the institutional setting. Human Resource Management Journal, 13, 56 70 .

47. Sharma, S. (2000). Managerial interpretations and organizational context as predictors of corporate choice of environmental strategy. Academy of Management Journal, 43, 681 - 697. doi:10.2307/1556361 